\title{
On Connotation of Social Responsibility of Higher Education
}

\author{
Shaolin Wang \\ Institute of Higher Education Research \\ Jilin Business and Technology College \\ Changchun, Jilin 130507 China
}

\begin{abstract}
Social responsibility of Higher Education Research refers to that in a strong sense of social care and educational care, researchers do independent thinking to "meet human needs and development and talent", and focus on "what a good society is, and what good education is, what kind of education can contribute to a better society". The current study of the social responsibility of higher education means that researchers need, not only from external factors, but also from their own factors to objectively and rationally contemplate to reflect the problems of Higher Education. Although the study of higher education has obtained certain achievements, there are still weak fundamental research theoretical issues, methodological system, and academic problems, such as lack of autonomy, which severely restricted and hindered the sustainable development of higher education and full play of its social responsibility. Therefore, China needs to re-examine the study of higher education and its current mission of "Science" and "internationalization", knowledge production and knowledge creation. Based on the inherent philosophy and their own logic, and conduct earnestly study of the practice of contemporary Chinese higher education, build ideological and theoretical system of diverse higher education with Chinese characteristics, making its own unique contribution to the study.
\end{abstract}

Keywords- Higher education, academic autonomy, social responsibility

\section{INTRODUCTION}

From a global perspective, interest of research on higher education is because that higher education is expanding in recent decades. Now, whether people are directly involved in higher education, its features and functions attach great importance to all members of society. In China, with the popularization of higher education, the scale of China's higher education has expanded rapidly. It has gradually become the community focus instead of the margins of society, and its impact on social and public life is growing. This means that higher education research can not only stay within their range of professional disciplines to meet the social responsibility as higher education research will get more and more attention. In this paper, on the basis of an overview of the literature review of higher education, it strives for a clear understanding of responsibilities of higher education and attempts to deepen researchers' sense of responsibility and mission of current China's Higher Education research by analyzing its concept, connotation, requirements and existing problems.

\section{CONNOTATION OF THE SOCIAL RESPONSIBILITY OF HIGHER EDUCATION AND ITS TYPE}

On social responsibility of higher education, it comes to different conclusions from different perspectives and different summary ways. This paper argues that higher education research is purposeful, conscious exploration and reflection of the theory and practice of higher education; it can be understood as a kind of social behavior. Specific social behavior has its specific purpose and mission, and it is what higher education research ought to do since the beginning; while specific social behavior will produce a specific result, thereby affecting the social development. And a party shall bear the responsibility for its consequences or affecting behavior. Typically, social responsibility is borne by the person or institution, and as the main investigator and research institutions, they should not only pay close attention to the field of higher education reform in different periods of development, but also explore consciousness and reflection coupled with the national and local development strategy. We must do things we ought to do, as well as can profoundly influence and guide the direction of society, and bear the responsibility for their behaviors.

Higher Education research should pay attention to social development, service the community - service obligations. Connotation of social development is very rich, focus of higher education is not all aspects of social development, but their own related fields such as: provide advice to government policy and decision-making; provide theoretical basis for educational decision-making and so on. $\mathrm{Xi}$ jia jun and its party people think that, "Higher Education research provide advices to the government, and actually higher education researchers and institutions as consultants. There are three primary responsibilities for higher education research, namely, pay close attention to the social action, knowledge production and organizational effectiveness. "While exploring educational research, Western scholars also found that government is quite confident about the research in the 1950s and 1960s, because it was generally believed that social science research can provide scientific and rational basis for education to solve the problem, the 
results of the study can be used directly as a basis for decision-making. "Professor Pan Bieyuan argued that" higher education theorists, though not policy makers, but there are obligations to identify the pros and cons, weigh advantages and disadvantages, and provide theoretical basis for educational decision-making under the law and the principles of fairness and efficiency of mutual relations. "

Predicting problems higher education may face, leading the development of society - lead responsibility. As mentioned earlier, higher education research should focus on practice and policy research, which is third-level tasks of higher education research, especially the development of national policies and local development strategy planning, the introduction of educational decision-making, etc., they are all need to study the predictive and proactive basis and objective foundation.

All of these require higher education study be carried out in a planned, proactive forecasting way, and it must consciously explore the unknown, find the problems, innovation, predict the future, take leading the society as its responsibility. Without scientific studies, there are hardly scientific decision-making. Higher Education in China in the 21 st century will face three major challenges, namely the contradiction of high-tech and low quality, the information superhighway entering colleges and universities and the traditional teaching process, popularization and inadequate investment, resulting in imbalance development in urban and rural areas. In this regard, Professor Pan Bieyuan holds that "to meet new challenges, prospective studies must be carried out, development strategies must be formulated to make higher education in China more brilliant in the 21st century." Cha Yong-jun also referred to "the reality that China's Higher Education Research chase 'hot spots', reflecting that higher education attempt to adapt to social development, followed by the needs of the community, reflecting the higher education research's passive adaptation to social relationship, Higher Education Research should have the service functions. The value of higher education research lies on its contribution to society, with the advanced theory, scientific thinking, forward-looking sense to lead social progress, these should be included in its responsibilities.

Close to the practice of higher education, to promote the reform and development -responsibility of the era. As an applied discipline, caring about real problem is the bounden duty of Higher Education. Wang Yongbin hold that "our society is in a comprehensive transformation and higher education is under realistic conditions of great change, worrying, confusing 'problems' are abound, they pose a challenge for higher education researchers, and need to be given an answer, the higher education researchers with a truly social responsibility and the spirit of the times can not avoid these problems. "Likewise, Aojie hold that" as a servant to the practice of higher education, they should clearly recognize their social responsibility, trying to avoid the quick success of an individual behavior-based study, when personal values and social values conflict, we should take social value as the most important ". An important responsibility of higher education is to study the actual concerns of the higher social transformation education reform, revealing the problems and answer the doubts, to provide guidance on the theory and methods of its development, to reflect the responsibilities of higher education research and existence value.

Accelerate the disciplines of higher education; contribute to higher education theory- Innovation responsibility. Innovation is the soul of theory. Without innovation, papers are also waste; in practice it is detrimental to society. Higher education disciplines belong to an object of theoretical research is between the first and second levels of the study. Higher education attempt to explore their theory has never stopped; it is always incumbent on higher education researchers and mission. Progress of the development of higher education theory with the pulsating era, the theory is reflected in practice disciplines to truly reflect the status of the development and reform of higher education in different periods of practice and extract regularities. Thus, the discovery of new methods, new ideas, new ideas, new models and new areas for higher education is critical for education theorists, they must constantly remind you to fulfill this responsibility duty and mission. Higher education researchers should effectively carry out their historical responsibility, aiming to open knowledge horizons, expand the space of thinking, both based on contemporary and tradition, both based in a foreign country and learning, and vigorously promote the academic point of view of innovation, system innovation and discipline research methods, the formation of the International School of Higher Education in China and strive to build discipline group of higher education with Chinese characteristics, Chinese style and Chinese style.

Follow the code of ethics in research, education and pure research teams - academic responsibility. All walks of life have their own ethical and moral standards, many scholars from the ethical point of view, points out the purpose of the education researcher, as a research subject, both in the conduct of research or research methods, should follow certain research ethics, this research ethics and common ethical and moral ethics and society is consistent. For example, engage in educational and research activities, requiring researchers to honor academic ethics, in compliance with academic standards, uphold academic conscience, have highly academic sense of responsibility; adhere to a pragmatic approach in academic research, behavioral research to prevent quick success, overcome the impetuous research culture and so on. As Song Bingbo said: "for the whole educational and research activities, the purpose of education research have a clear ethical concern, it is not only concerned about the human condition, but also concerned about the prospects for the development of people, and more concerned with harmony between society and person." 


\section{HOW HIGHER EDUCATION RESEARCHERS BEAR SOCIAL RESPONSIBILITY}

\section{A. The researchers should continue to learn and master a broad range of knowledge and improve theoretical knowledge}

Higher education investigator study higher education, and higher education is a complex, multi-level system, for which you need to master a wealth of knowledge, especially theoretical knowledge from multiple disciplines and scientific research methods and having these knowledge is possible to fulfill our social responsibilities. For example, on the "popularization of higher education", if from the education perspective, researchers may focus only on the security aspects of the quality of education, teacher-student ratio, student funding, the amount of student books, etc. Obviously, this only from education perspectives is difficult to comprehensive, deeply understand this popular issue, but if you also have a broad knowledge of research in other disciplines, then the problem should be more comprehensive. With the knowledge of sociology, it can pay attention to the expansion of higher education and society hierarchical relationship, pay attention to the "fairness"; with knowledge of economics, you can concern the expansion and industrial development, the relationship between economic structure, pay attention to the "efficiency"; with knowledge of psychology, you can concern about school expansion arising from psychological changes among groups of students and student group interaction problems, etc. In short, researchers need to continue to learn and enhance their theoretical knowledge of literacy, whether it is formulated to promote policies, practices, or explore an intermediary, directly participate in practice, or research, it has a solid foundation of knowledge and have the ability to take social responsibility.

\section{B. Researchers should have "discipline", and the academic community to conduct "discipline"}

Researchers should have self-discipline and courage to bear social responsibility. For his commitment to social responsibility, these researchers rely, to a greater extent, on self-accountability. If you have a strong "self" consciousness, it will not take up their responsibilities mere formality, not talk nonsense, or lie without action. In addition, the researchers should assume social responsibility; they can also rely on the academic community constraints. Higher
Education in China since the 1980s, with standardization stage of development, there are 700-800 in higher education institutes of higher education, as well as 17 doctoral and 83 master's degree. We can say that higher education academic community has been studying this form of academic staff with strong academic influence and binding. Based on this study of higher education, academic community should strengthen the group's sense of social responsibility to create a culture of social responsibility. There, they share the belief of the theory, methodology, techniques and issues. Academic community with such a sense of responsibility and accountability culture, will play for the academic regulations making use of individual members, so that researchers keep in mind their social responsibility, recognizing that fulfill this responsibility is the academic community requirements, and fail to fulfill those responsibilities will be blamed and criticized by the academic community.

\section{CONCLUSION}

Half a century ago, some scholars have pointed out, "People are often accused that universities research everything but themslves, and they are all ready to reform everything but themslves." Today, the situation has gone. China has become a big country doing higher education research; higher education reform is also ongoing. At present, the accused may be needed, higher education researchers have learned that higher education is not the study of their own; they require for all aspects of the reform while higher education is rarely asked for their "reform", then, let us ask ourselves and carefully study their social responsibilities and how to fulfill this responsibility!

\section{REFERENCES}

[1] Maoyuan, Fang Zeqiang. On Social Responsibility of Higher Education [J] Higher Education Management,2012,06:1 -5.

[2] LizheYu, Zhao Fengjuan. New Exploration Victor Higher Education Research Social Responsibility [J]. Longyan University,2011,01:1 -4.

[3] Zhou Tingyong. Reflections on the social responsibility of higher education research $[\mathrm{J}]$. Chinese Higher Education Research,2011,06:20-23.

[4] Wuyi Ying, Yeai Zhen. Social Responsibility and Higher Education Research principal mission of higher education research $[\mathrm{J}]$. Chinese Higher Education Review,2011,00:37-47. 